\title{
Poly- $\varepsilon$-Caprolactone Microsphere Polymers Containing Usnic Acid: Acute Toxicity and Anti-Inflammatory Activity
}

\author{
Jéssica A. P. Barbosa, ${ }^{1}$ Eryvelton S. Franco, ${ }^{2}$ Camilla V. N. S. Silva, ${ }^{3}$ \\ Tatiane O. Bezerra, ${ }^{1}$ Marllon A. N. Santana, ${ }^{1}$ Carlson H. R. C. Júnior, ${ }^{1}$ \\ Teresinha G. Silva, ${ }^{1}$ Noemia P. S. Santos, ${ }^{4}$ and Maria B. S. Maia ${ }^{2}$ \\ ${ }^{1}$ Department of Antibiotics, Federal University of Pernambuco, Recife, PE, Brazil \\ ${ }^{2}$ Department of Physiology and Pharmacology, Federal University of Pernambuco, Recife, PE, Brazil \\ ${ }^{3}$ Department of Pharmaceutical Sciences, Federal University of Pernambuco, Recife, PE, Brazil \\ ${ }^{4}$ Laboratory of Biotechnology and Pharmaceuticals, Academic Center of Vitória, \\ Federal University of Pernambuco, Vitória de Santo Antão, PE, Brazil
}

Correspondence should be addressed to Maria B. S. Maia; mbsm@ufpe.br

Received 15 May 2017; Accepted 9 October 2017; Published 4 December 2017

Academic Editor: P. Tresina Soris

Copyright (C) 2017 Jéssica A. P. Barbosa et al. This is an open access article distributed under the Creative Commons Attribution License, which permits unrestricted use, distribution, and reproduction in any medium, provided the original work is properly cited.

Usnic acid (UA) has been studied by its pharmacological properties; however, it presents moderate toxicity, low solubility, and absorption by biological membranes. The aim of this study was to develop poly-e-caprolactone microsphere polymers containing UA (UA-micro) and evaluate their acute toxicity and anti-inflammatory activity. The microspheres were prepared by multiple emulsion technique (water/oil/water) and characterized by the encapsulation efficiency, particle size, polydispersity index, and zeta potential. The acute toxicity of UA and UA-micro $(25-50 \mathrm{mg} / \mathrm{kg} ;$ p.o.) was evaluated in mice. The anti-inflammatory activity of UA and UA-micro was evaluated by subcutaneous air pouch and carrageenan-induced paw edema in rat, with measurement of inflammatory cytokines and MPO levels. The UA presented encapsulation efficiency of $97.72 \%$, particle size of 13.54 micrometers, polydispersity index of 2.36, and zeta potential of $44.5 \pm 2.95 \mathrm{mV}$. The UA-micro presented lower acute toxicity $\left(\mathrm{LD}_{50}\right.$ value up to $2000 \mathrm{mg} / \mathrm{kg}$; p.o.) when compared to UA. UA-micro and UA $(25 \mathrm{mg} / \mathrm{kg})$ significantly reduced paw volume and decreased MPO levels, whereas only UA-micro $(50 \mathrm{mg} / \mathrm{kg}$ ) reduced significantly IL- $1 \beta$, TNF- $\alpha$, and NO levels in inflammatory exudate. These results suggest that controlled release systems, as microspheres, can be a promising alternative to reduce the toxicity of UA, making it a viable compound for inflammation therapy.

\section{Introduction}

Inflammation is a complex process involving several cell types and molecular mediators, whose main goals are to isolate, neutralize, and destroy harmful agents, following tissue regeneration stimuli [1]. Although nonsteroidal antiinflammatory use in therapeutics has its efficacy, prolonged treatment may be responsible for gastrointestinal side effects, such as superficial mucous membrane alterations, erosive gastritis, and peptic ulcer related to prostaglandins inhibition, produced via COX-1 [2]. There is a growing search for new anti-inflammatory agents from natural products, mainly for compounds that have therapeutic and pharmacological potential, reduced side effects, and low cost [3].

Usnic acid (2,6-diacetyl-7,9-dihydroxy-8,9b-diethyl-1,3(2H, 9bH)-benzofuran, $\mathrm{C} 18 \mathrm{H} 16 \mathrm{O} 7)$, a secondary metabolite isolated from lichens $[4,5]$, has been highlighted for presenting several biological activities, such as anti-inflammatory, analgesic [6], antimicrobial [7], gastroprotective, antioxidant [8], anticancer [9], and tissue healing activities [10]. Although usnic acid has a great variety of biological activities, its utilization as therapeutic agent is not possible yet due to its physicochemical properties, such as low solubility, high toxicity, and impaired interaction with cell barriers [11, 12]. 
Issues regarding usnic acid administration can be overcome through a controlled-release drug system that can reduce usnic acid toxicity and increase therapeutic efficacy.

The controlled-release drug system was designed to slowly and continually release the drug, keeping the desired concentration in the blood for a longer period. One of the controlled-release drug systems is microspheres, which are polymeric solid particles (usually spherical) that deserve highlight due to physicochemical and biological stabilities. In addition, microspheres are utilized for encapsulation of several substances, such as peptides, proteins, DNA/RNA, and drugs $[13,14]$. Encapsulation of usnic acid into microspheres may overcome boundaries regarding low solubility and difficult absorption through cell membranes to reduce the toxic effects caused by free usnic acid, which may increase its biological effect.

\section{Materials and Methods}

2.1. Animals. Male Wistar rats (190-200 g) and female Swiss mice (30-35 g) from the vivarium of Antibiotics Department, Federal University of Pernambuco (UFPE), were used. Animals were kept in polypropylene boxes in a room with controlled temperature $\left(22 \pm 2^{\circ} \mathrm{C}\right)$ and light-dark cycle of $12 \mathrm{~h} / 12 \mathrm{~h}$. Water and food were available ad libitum. Experimental protocols were approved by the Animal Studies Committee (CEEA) of the UFPE, under process number 23076.052269/2012-35.

2.2. Reagents. All the reagents (poly- $\varepsilon$-caprolactone, polyvinyl alcohol (MW: 30.000-70.000), polyethylene glycol (MW: 3.350), usnic acid, trehalose, indomethacin, and carrageenan type IV) were obtained from Sigma-Aldrich (St. Louis, USA).

2.3. Preparation of PCL Microspheres Containing Usnic Acid. Microspheres were prepared using multiple emulsion method following solvent evaporation [15]. One simple emulsion was prepared by dissolving $225 \mathrm{mg}$ of poly- $\varepsilon$-caprolactone and $25 \mathrm{mg}$ of usnic acid into dichloromethane $(6 \mathrm{~mL})$. The organic solution was emulsified (Ultra-Turrax T-25, IKA) with $125 \mathrm{mg}$ of polyethylene glycol into water for $1 \mathrm{~min}$ at $6848 \times \mathrm{g}$. The produced emulsion was added to an aqueous phase constituted by polyvinyl alcohol (1.25\%) and was emulsified during $30 \mathrm{~s}$ at $6848 \times \mathrm{g}$, resulting in multiple emulsions. The final emulsion was kept under agitation at $17 \times \mathrm{g}$ for 2 hours. Microspheres were centrifuged at $963 \times \mathrm{g}$ for 10 minutes and dispersed into trehalose $1 \%(\mathrm{~m} / \mathrm{v})$. Subsequently, microspheres were frozen at $-80^{\circ} \mathrm{C}$ and lyophilized afterwards.

\subsection{Physicochemical Characterization of Poly-E-Caprolactone} Microspheres Containing Usnic Acid. Usnic acid encapsulation efficiency in the microspheres was determined by spectrophotometry (Ultrospec 3000, Amersham Pharmacia Biotech, USA). Lyophilized microsphere samples (5 mg) were diluted in a dichloromethane: methanol $(3: 2)$ mixture and submitted to sonication for $10 \mathrm{~min}$. An aliquot of this solution was diluted to a theoretical concentration of $6 \mu \mathrm{g} \cdot \mathrm{mL}^{-1}$. Usnic acid was determined by spectrophotometry (280 nm) using a standard curve of $3-10 \mu \mathrm{g} \cdot \mathrm{mL}^{-1}$ in acetonitrile.

Microsphere particles size was determined through laser diffraction technique using a particle analyzer (Zetasizer Nano ZS90, Malvern, UK) [16]. Lyophilized microsphere samples $\left(10 \mathrm{mg}\right.$ ) were dispersed into a Tween ${ }^{\circledR} 80$ aqueous solution at $0.04 \%(\mathrm{w} / \mathrm{v})$ and submitted to sonication for $10 \mathrm{~min}$. Calculated parameters were as follows: volume median diameter (VMD) and span index, calculated by span equation $=(d(v ; 0.9)-d(v ; 0.1)) / d(v ; 0.5)$, where $d(v ; 0.9), d(v$; $0.1)$, and $d(v ; 0.5)$, represent the percentage of microspheres with volume median diameter above $90 \%, 10 \%$, and $50 \%$, respectively.

Surface charge (zeta potential) was determined by electrophoretic mobility method using the Zetasizer Nano ZS90 (Malvern, UK) equipment and Zetasizer software. Microsphere zeta potential $(\zeta)$ was measured after dilution into an aqueous solution of $1 \mathrm{Mm} \mathrm{NaCl}(0.5 \%, \mathrm{p} / \mathrm{v})$ at $25^{\circ} \mathrm{C}$.

2.5. Acute Toxicity. Acute toxicity tests were designed following the "Acute Toxic Class Method" [17]. Mice were divided into five groups ( $n=3$ animals/group). Experiments were repeated using the same animal quantity, with a total of 6 animals/group. The control group received vehicle $(0.9 \% \mathrm{NaCl}$ : $5 \%$ Cremophor; p.o.) and experimental groups received usnic acid (UA, 2000, 300, and $50 \mathrm{mg} / \mathrm{kg}$; p.o.), poly- $\varepsilon$-caprolactone microsphere polymers containing usnic acid (UA-micro, $2000 \mathrm{mg} / \mathrm{kg}$; p.o.), or indomethacin (10 mg/kg; p.o.). Animals were observed during the first 8 and 24 hours during 14 days after compound administration and had toxicity signals scored. On the last day of observation, animals were euthanized in a $\mathrm{CO}_{2}$ chamber and had their organs (liver and kidney) removed for histopathological analysis.

2.6. Histopathological Analysis. Necropsy of animals submitted to acute toxicity was performed and the organs (liver and kidney) were kept in neutral buffered formalin (10\%) for $48 \mathrm{~h}$ at room temperature. Then, organs were submitted to dehydration using ethyl alcohol in different concentrations, diaphanized in xylol, impregnated, and included in paraffin. Samples were sliced into a microtome adjusted to $5 \mu \mathrm{m}$. Histological slices were kept in an incubator at $37^{\circ} \mathrm{C}$ for $24 \mathrm{~h}$ in order to dry. Subsequently, slices were tinted with hematoxylin-eosin stain (H\&E). Analysis was made using optical microscope.

2.7. Carrageenan-Induced Paw Edema. Paw edema test was performed according to Winter et al. [18]. Five Wistar rat groups ( $n=5$ animals/group) were treated orally with UA $(25 \mathrm{mg} / \mathrm{kg})$, UA-micro (25 and $50 \mathrm{mg} / \mathrm{kg}$ ), indomethacin $(10 \mathrm{mg} / \mathrm{kg})$, or vehicle. One hour after treatments, $0.1 \mathrm{ml}$ of a commercially prepared carrageenan was inoculated into the right hind of animals. The volume of the hind paw swelling $(\mathrm{ml})$ was measured with an electronic water plethysmometer (Ugo Basile, Italy) at zero minutes (before) and 1, 2, 3, and $4 \mathrm{~h}$ after a carrageenan injection.

2.8. Myeloperoxidase (MPO) Levels Quantification. Paw tissues of animals submitted to paw edema test were collected 6 hours after carrageenan administration. Samples were 
weighted, ground, and kept in phosphate buffer $[50 \mathrm{mM}$, $\mathrm{pH}$ 6.0, and $0.5 \%$ hexadecyltrimethylammonium bromide (HTAB, Sigma Chem. Co, USA)]. Samples were centrifuged at $12.000 \times \mathrm{g}$ for 2 minutes at $4^{\circ} \mathrm{C}$. Each well in a 96-well plate was filled with $5 \mu \mathrm{L}$ of centrifuged supernatant and $200 \mu \mathrm{L}$ of o-dianisidine dihydrochloride solution (Sigma Chem. Co, USA; $0,167 \mathrm{mg} / \mathrm{mL}$, prepared in $50 \mathrm{mM}$ potassium phosphate buffer with $0.005 \% \mathrm{H}_{2} \mathrm{O}_{2}$ ) following spectrophotometer reading $(450 \mathrm{~nm})$. Results were expressed in MPO units (UMPO/mg of tissue), considering that $1 \mathrm{UMPO}$ corresponds to the quantity that one enzyme degrades with $1 \mu \mathrm{moL}$ per minute [19]. The test was performed in duplicates.

2.9. Subcutaneous Air Pouch (SAP) Test. Anti-inflammatory activity was evaluated through air pouch formation by injection of $2.5 \mathrm{~mL}$ of sterile air on day 0 in the dorsal region of the mice, followed by a second injection of $2.5 \mathrm{~mL}$ of sterile air three days after the first. On the sixth day, according to their group, the animals received orally vehicle, UA ( $25 \mathrm{mg} / \mathrm{kg}$; p.o.), UA-micro (25 and $50 \mathrm{mg} / \mathrm{kg}$ ), or indomethacin $(10 \mathrm{mg} / \mathrm{kg})$. One hour after treatments, inflammation was induced by injection of $1 \mathrm{~mL}$ carrageenan (1\%) inside the air pouch. After $6 \mathrm{~h}$, animals were euthanized in a $\mathrm{CO}_{2}$ chamber and had the pouch washed with $3 \mathrm{~mL}$ of PBS containing $3 \mu \mathrm{Mol}$ EDTA. Polymorphonuclear leukocytes quantification on the lavage fluid was performed using an ABX Micros 60 hematology analyzer [20, 21].

2.10. Nitric Oxide (NO) Quantification. To access nitric oxide (NO) production, nitrate concentrations (NO stable metabolite) were quantified in the air pouch exudate through air pouch test. One sample aliquot of $50 \mu \mathrm{L}$ was transferred into a microplate and incubated with $50 \mu \mathrm{L}$ Griess reagent (sulfanilamide $1 \%$, naphthyl ethylenediamine dichlorohydrate $0.1 \%$, and $\mathrm{H}_{3} \mathrm{PO}_{4} 5 \%$ ) for $10 \mathrm{~min}$ at room temperature in the dark. Absorbance $(540 \mathrm{~nm})$ was obtained using a microplate reader and nitrate concentration was calculated using a sodium nitrate standard curve [22].

2.11. TNF- $\alpha$ and IL-1 $\beta$ Quantification. TNF- $\alpha$ and IL- $1 \beta$ quantification was accessed using specific ELISA kits for mice, following manufacturer's instructions (BD Biosciences, San Diego, California, USA). The lower limit of detection was $10 \mathrm{pg} / \mathrm{mL}$.

2.12. Statistical Analysis. Results were expressed as mean \pm standard deviation for each experimental group using GraphPad Prism software (version 6.0; DEMO). Data were analyzed through one-way Analysis of Variance (ANOVA) followed by Tukey's test, except for paw edema test, which was analyzed through two-way Analysis of Variance (ANOVA) followed by Bonferroni multiple comparison test. Confidence intervals of $95 \%$ and " $p$ " values lower than $0.05(p<0.05)$ were considered as indicators of statistical significance.

\section{Results}

3.1. Physicochemical Characterization of Poly-E-Caprolactone (PCL) Microspheres Containing Usnic Acid. Encapsulation efficiency was obtained through three analytic curves, which were prepared from different stock solutions, and adjusted through linear regression analysis. The equation mean that was obtained from three calibration curves was $y=0.07309 x$ +0.00263 , where $y$ is the absorbance $(\mathrm{nm})$ and $x$ is the concentration $(\mu \mathrm{g} / \mathrm{mL})$ in usnic acid equivalents. The correlation coefficient was 0.99989 , meaning that $99.98 \%$ of the total variation around the mean was explained by linear regression. Usnic acid was encapsulated into PCL microspheres with efficiency of $97.72 \pm 0.0004 \%$. UA-micro zeta potential $(\zeta)$ had a higher negative value $(\zeta=-44.5 \pm 2.95 \mathrm{mV})$ when compared to PCL microspheres $(\zeta=-26.9 \pm 0.58 \mathrm{mV})$ (Table 1).

In this study, the grain size of microspheres with usnic acid was also verified, which was $13.54 \mu \mathrm{m}$, while microspheres without usnic acid size had grain size of $9.37 \mu \mathrm{m}$ (Table 1). Microspheres without usnic acid (PCL microspheres) showed polydispersion index (span) of 2.18, while the UA-micro span was 2.36, which suggests homogenous formulations.

3.2. Acute Toxicity. Acute toxicity grade and physiological parameters (water and food intake, weight gain, and mortality) are presented in Table 2 . The animals of UA-treated group $(2000 \mathrm{mg} / \mathrm{kg}$; p.o.) presented clinical symptoms of toxicity (irritability, vocal fremitus, and abdominal contortion) in the first 2 hours of observation, followed by death. Regarding the group treated with UA (300 mg/kg; p.o.), reduced food intake and weight loss were observed when compared to the control group. On the other hand, no indication of acute toxicity or occurrence of death was observed in the groups treated with UA-micro ( $2000 \mathrm{mg} / \mathrm{kg}$; p.o.) or UA $(50 \mathrm{mg} / \mathrm{kg}$; p.o.) as compared to the control group.

3.3. Histopathological Analysis. In control animals, no morphological kidney tissue damage was detected (Figure 1(a)). The UA-micro-treated group $(2000 \mathrm{mg} / \mathrm{kg}$; p.o.) showed slight derangement of the simple cuboidal epithelium of convoluted tubules and vacuolation presence, while renal corpuscles were kept preserved (Figure 1(b)). On the other hand, as compared to control group, the UA-treated animals ( $2000 \mathrm{mg} / \mathrm{kg}$; p.o.) exhibited serious kidney damage, indicated by intense nuclear acidophilia and cytoplasmic vacuolation, capsular space and convoluted tubules lumen size increase, fluid accumulation between the basal membrane and cuboidal epithelial cells of the convoluted tubes, and cytoplasmic material accumulation in the renal tubules and cell lysis (Figure 1(c)). Morphological changes with some damage in kidney tissue were observed in animals treated with UA at dose of $300 \mathrm{mg} / \mathrm{kg}$ (p.o.) (increasing capsular space and leukocyte infiltration) (Figure $1(\mathrm{~d})$ ) or $50 \mathrm{mg} / \mathrm{kg}$ (p.o.) (renal tubules nuclei number increased, showing cytoplasmic vacuolation (Figure 1(e)).

Concerning hepatic tissue, no abnormalities were observed in control group (Figure 2(a)). The UA-microtreated animals $(2000 \mathrm{mg} / \mathrm{kg}$ p.o.) showed plates of hepatic cells and sinusoids but preserved hepatocytes nuclei (Figure 2(b)). However, in mice treated with UA (2000 mg/kg; p.o.), hepatic cell plates derangement, intense vacuolation, inflammatory influx, cytoplasmic acidophilia, and decharacterization of the nucleus of hepatocytes were observed 
TABLE 1: Encapsulation efficiency, mean particle size $\left(d_{v}\right)$, polydispersion (span), and zeta potential $(\zeta)$ of PCL microspheres with (UA-micro) and without usnic acid (PCL microspheres). Results were expressed as mean \pm SD.

\begin{tabular}{lcccc}
\hline Drug: polymer & Encapsulation efficiency $\pm \mathrm{DP}^{*}(\%)$ & $d_{v}(\mu \mathrm{m})$ & Span & Zeta potential $(\zeta) \pm \mathrm{DP}{ }^{*}(\mathrm{mV})$ \\
\hline PCL microspheres & - & 9.37 & 2.18 & $-26.9 \pm 0.58$ \\
UA-micro & $97.72 \pm 0,00$ & 13.54 & 2.36 & $-44.5 \pm 2.95$ \\
\hline
\end{tabular}

${ }^{*}$ SD: standard deviation.

TABLE 2: Usnic acid (UA) and encapsulated usnic acid (UA-micro) effects over Swiss mice physiological parameters ( $n=6$ animals/group).

\begin{tabular}{|c|c|c|c|c|c|c|}
\hline \multirow{2}{*}{ Groups } & \multirow{2}{*}{$\begin{array}{c}\text { Dose/p.o. } \\
\mathrm{mg} / \mathrm{kg}\end{array}$} & \multirow{2}{*}{$\begin{array}{c}\text { Number of } \\
\text { deaths }\end{array}$} & \multirow{2}{*}{$\begin{array}{l}\text { Food consumption } \\
\text { (g/day) }\end{array}$} & \multirow{2}{*}{$\begin{array}{l}\text { Water consumption } \\
(\mathrm{mL} / \text { day })\end{array}$} & \multicolumn{2}{|c|}{ Body weight (g) } \\
\hline & & & & & Early & End \\
\hline Control & & $0 / 6$ & $25.11 \pm 2.3$ & $45.8 \pm 1.3$ & $32.6 \pm 2.77$ & $33.0 \pm 3.2$ \\
\hline UA-micro & 2000 & $0 / 6$ & $25.52 \pm 2.2$ & $46.4 \pm 2.1$ & $30.3 \pm 3.02$ & $32.3 \pm 1.2$ \\
\hline UA & 2000 & $6 / 6$ & - & - & $29.7 \pm 1.34$ & - \\
\hline UA & 300 & $0 / 6$ & $20.61 \pm 2.4^{* * *}$ & $44.4 \pm 1.2$ & $28.9 \pm 1.27$ & $30.3 \pm 1.0^{* *}$ \\
\hline UA & 50 & $0 / 6$ & $23.75 \pm 2.5$ & $46.6 \pm 3.1$ & $30.6 \pm 0.34$ & $32.8 \pm 1.84$ \\
\hline
\end{tabular}

${ }^{* *} p<0.01$ and ${ }^{* * *} p<0.0001$ when compared with control group.

TABLE 3: Anti-inflammatory effect of free usnic acid (UA), encapsulated usnic acid microspheres (UA-micro), and indomethacin on carrageenan induced rat paw edema model ( $n=5$ animals/group).

\begin{tabular}{lcccc}
\hline Groups & & \multicolumn{2}{c}{ Variation of paw volume $(\mathrm{mL})$} \\
& $60 \mathrm{~min}$ & $120 \mathrm{~min}$ & $180 \mathrm{~min}$ & $240 \mathrm{~min}$ \\
\hline Vehicle (control) & $0.61 \pm 0.05$ & $1.25 \pm 0.09$ & $1.62 \pm 0.09$ & $1.30 \pm 0.07$ \\
UA 25 mg/kg & $0.32 \pm 0.02^{*}$ & $0.50 \pm 0.04^{*}$ & $1.10 \pm 0.11^{*}$ & $0.81 \pm 0.14^{*}$ \\
UA-micro 25 mg/kg & $0.30 \pm 0.03^{*}$ & $0.45 \pm 0.05^{*}$ & $0.87 \pm 0.06^{* \#}$ & $0.68 \pm 0.05^{* \#}$ \\
UA-micro 50 mg/kg & $0.26 \pm 0.01^{*}$ & $0.40 \pm 0.03^{*}$ & $0.63 \pm 0.03^{* \#}$ & $0.48 \pm 0.03^{* \#}$ \\
Indomethacin 10 mg/kg & $0.18 \pm 0.02^{*}$ & $0.30 \pm 0.03^{*}$ & $0.40 \pm 0.03^{*}$ & $0.29 \pm 0.02^{*}$ \\
\hline
\end{tabular}

Values are expressed as mean $\pm \mathrm{SD}$ ( $n=5 /$ group). ${ }^{*}$ Significantly different from the control group, $p<0.05$ (control versus UA $25 \mathrm{mg} / \mathrm{kg}$; UA-micro $25 \mathrm{mg} / \mathrm{kg}$; and UA-micro $50 \mathrm{mg} / \mathrm{kg}$ ). " Significantly different from the UA $25 \mathrm{mg} / \mathrm{kg}$ group, $p<0.05$ (UA $25 \mathrm{mg} / \mathrm{kg}$ versus UA-micro $25 \mathrm{mg} / \mathrm{kg}$ and UA-micro $50 \mathrm{mg} / \mathrm{kg}$ ).

(Figure 2(c)). In UA-treated group $(300 \mathrm{mg} / \mathrm{kg})$, granule cytoplasmic accumulation, cytoplasmic vacuolation, hepatic cell plates derangement, and slight decharacterization of the hepatocyte nucleus (Figure 2(d)) were observed. In UA-treated animals ( $50 \mathrm{mg} / \mathrm{kg}$; p.o.), hepatic cell plates were preserved, such as the hepatocyte nuclei, while almost no cytoplasmic granules were preserved (Figure 2(e)).

3.4. Carrageenan-Induced Paw Edema. Table 3 shows the evolution of paw edema in control and experimental groups. The rat paw edema volume in UA- (25 mg/kg; p.o.), UAmicro- (25 and $50 \mathrm{mg} / \mathrm{kg}$; p.o.) or indomethacin- $(10 \mathrm{mg} / \mathrm{kg}$; p.o.) treated animals differs markedly from that observed in the corresponding control animals (Figure 1). As can be observed, the anti-inflammatory activity of free usnic acid (UA) was preserved when it was encapsulated in microspheres (UA-micro). In addition, this activity was dosedependent and comparable to that presented by indomethacin $(10 \mathrm{mg} / \mathrm{kg}$; p.o.) in the time points of 1 and 2 hours.

3.5. Myeloperoxidase (MPO) Quantification. As can be seen in Figure 3, baseline MO levels were significantly different in experimental and control groups. On the other hand, no significant differences among UA (25 mg/kg; p.o.), UA-micro
(25 and $50 \mathrm{mg} / \mathrm{kg}$; p.o.), or indomethacin (10 mg/kg; p.o.) were observed regarding MO levels (Figure 3).

3.6. Polymorphonuclear Leukocytes Migration. The treatment with UA (25 mg/kg; p.o.), UA-micro (25 and $50 \mathrm{mg} / \mathrm{kg}$; p.o.), or indomethacin $(10 \mathrm{mg} / \mathrm{kg}$; p.o.) significantly reduced leukocytes migration to injured paws (Table 4). The neutrophil count was correlated with myeloperoxidase only in the CKD group.

3.7. TNF- $\alpha, I L-1 \beta$, and Nitric Oxide (NO) Levels. Significant reductions were also observed in TNF- $\alpha$ (Figure 4), IL-1 $\beta$ (Figure 5), and NO (Figure 6) levels. In a dose-dependent manner, UA-micro inhibited the release of these chemical mediators from inflammation, whereas indomethacin (10 mg/kg; p.o.) reduced NO levels.

\section{Discussion}

Usnic acid, a secondary metabolite of lichen, is of great interest in pharmacological research. However, this compound has been associated with severe liver damage (hepatotoxicity) when taken as a dietary supplement. The anti-inflammatory activity of usnic acid has been described in the literature by several researchers using in vitro and in vivo assays $[6,23]$ 


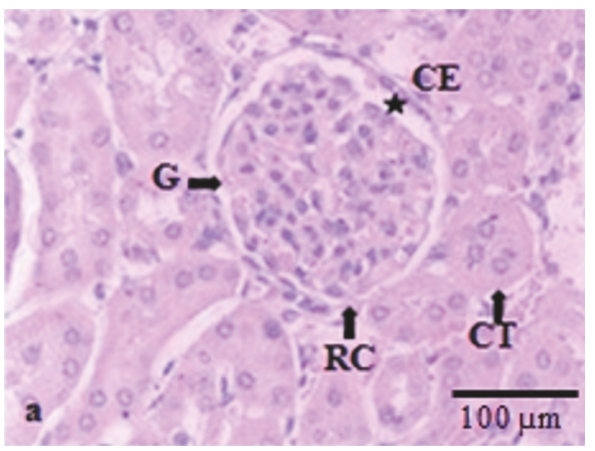

(a)

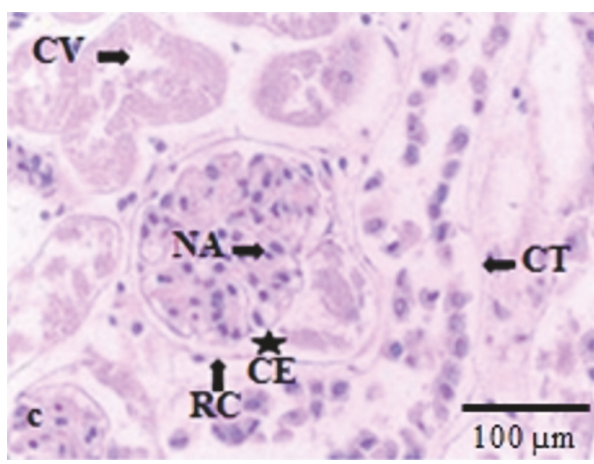

(c)

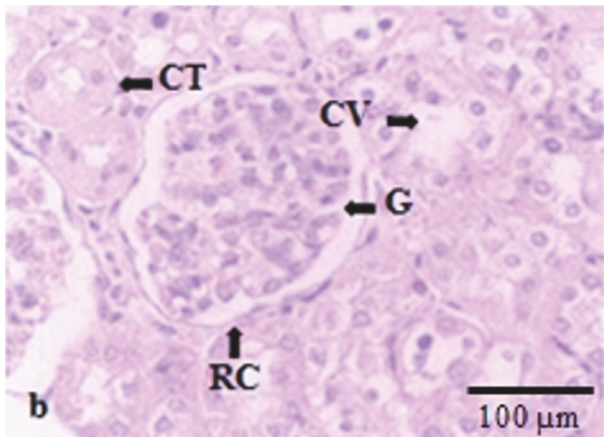

(b)

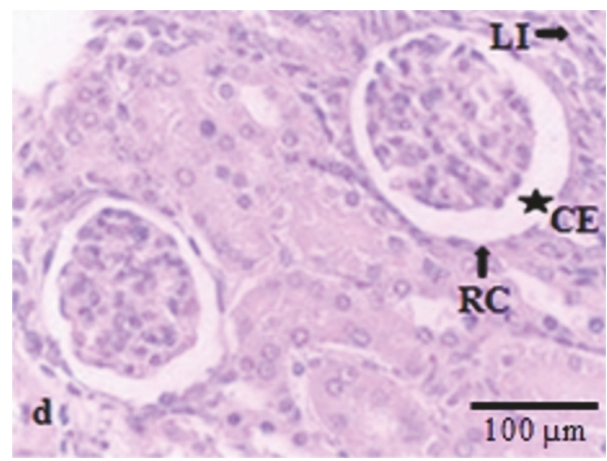

(d)

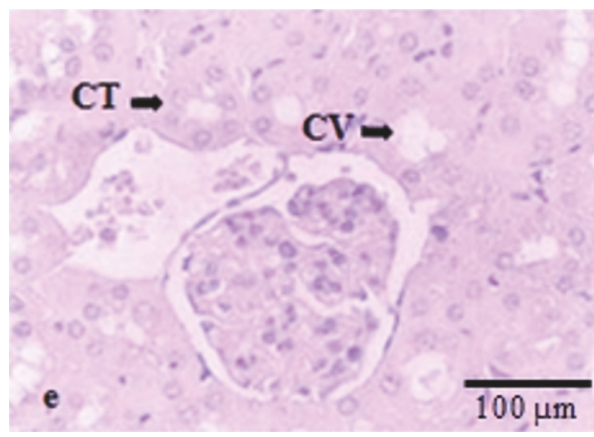

(e)

Figure 1: Kidney sections of (a) control, (b) UA-micro (2000 mg/kg; p.o.), (c) UA (2000 mg/kg; p.o.), (d) UA (300 mg/kg; p.o.), and (e) UA $(50 \mathrm{mg} / \mathrm{kg} ;$ p.o.). RC: renal corpuscle; CS: capsular space; LI: leukocytes infiltrate; CT: convoluted tubules; G: glomerulus; CV: cytoplasmic vacuolation; NA: nuclear acidophilia ( $\times 400$ magnification $)$.

TABLE 4: Effect of free usnic acid (UA) and encapsulated usnic acid microspheres (UA-micro) on neutrophils migration.

\begin{tabular}{lccc}
\hline Groups & Dose $(\mathrm{mg} / \mathrm{kg}$ p.o. $)$ & Leukocytes migration $\left(10^{3} / \mathrm{mm}^{3}\right)$ & Inhibition\% \\
\hline Control & - & $11.4 \pm 1.17$ & - \\
UA & 25 & $5.8 \pm 0.68^{*}$ & 49 \\
UA-micro & 25 & $7.8 \pm 0.67^{*}$ & 31 \\
UA-micro & 50 & $3.8 \pm 0.49^{* \#}$ & 67 \\
Indomethacin & 10 & $3.6 \pm 0.76^{*}$ & 68 \\
\hline
\end{tabular}

Data are shown as mean $\pm \mathrm{SD}$ ( $n=5$ /group) and the statistical significance between groups was determined using Analysis of Variance (ANOVA) followed by Turkey's test. ${ }^{*} p<0,0001$ versus control. ${ }^{\#}$ Nonsignificant versus indomethacin. 


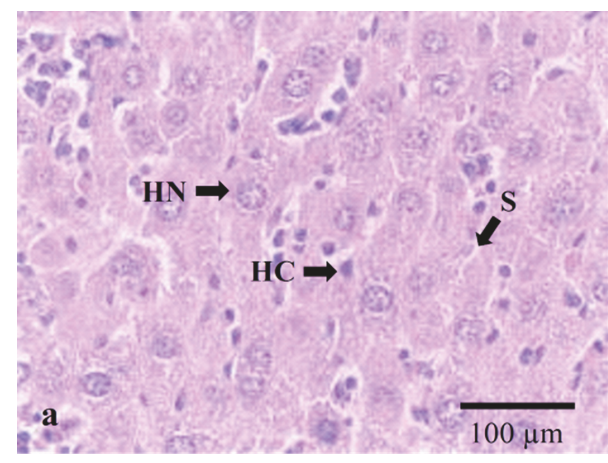

(a)

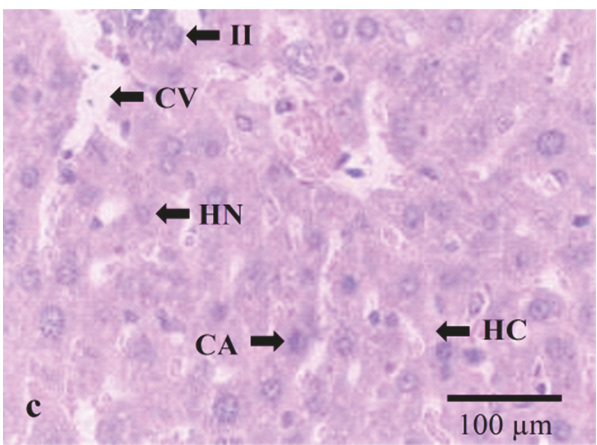

(c)

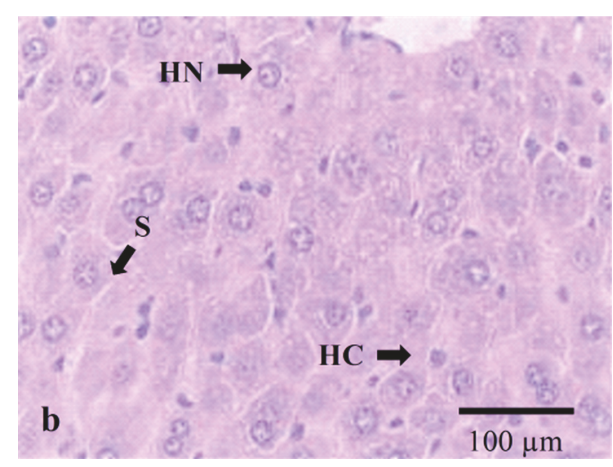

(b)

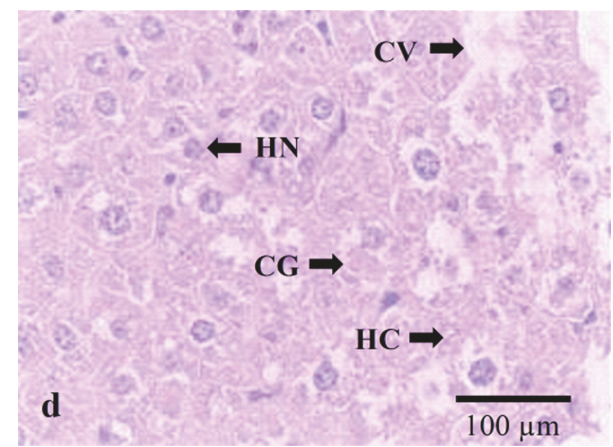

(d)

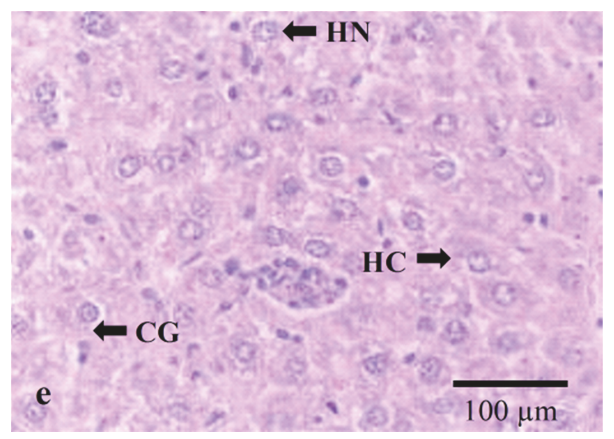

(e)

Figure 2: Liver sections of (a) control, (b) UA-micro (2000 mg/kg; p.o.), (c) UA (2000 mg/kg; p.o.), (d) UA (300 mg/kg; p.o.), and (e) UA $(50 \mathrm{mg} / \mathrm{kg} ;$ p.o.). S: hepatic sinusoids; HN: hepatocyte nucleus; HC: hepatic cell plates; CV: cytoplasmic vacuolation; II: inflammatory influx; CA: cytoplasmic acidophilia; CG: cytoplasmic granules ( $\times 400$ magnification).

(Su et al., 2014). In this context, our work aimed to compare the anti-inflammatory activity and acute toxicity of UA incorporated in poly- $\varepsilon$-caprolactone (PLC) microspheres (UAmicro) and free UA.

In relation to microsphere physicochemical characterization, our results showed that UA encapsulation into microparticles was satisfactory and suggest its further use for UA delivery application. Other drugs with similar hydrophobic characteristics to UA, such as paclitaxel [24], ibuprofen [25], and transdehydrocrotonin [11], and UA itself [26] showed high encapsulation efficiency into microspheres. Our results also showed that UA incorporated into PCL matrix microspheres increased microparticles size. Thus, it is possible to suggest that particles are homogeneous once polydispersion values (span) vary from 1.1 to 3.3. These data allow us to classify size distribution as monomodal, which is acceptable for controlled-release oral system [26]. Zeta potential can be used to determine microparticles surface charge and indicate their stability when in suspension. Moreover, their negative charge could be associated with the presence of drug molecules adsorbed on the microsphere polymer wall, which can influence surface charge [14].

Consistently, as incorporated into poly- $\varepsilon$-caprolactone microsphere polymers (UA-micro), UA showed reduced toxicity degree and maintained its anti-inflammatory activity. The downregulated acute toxicity verified in UA-micro ( $\mathrm{LD}_{50}$ value up to $2000 \mathrm{mg} / \mathrm{kg}$; p.o.) can be explained by its incorporation into microspheres. According to Chen et al. [27], poly- $\varepsilon$-caprolactone microparticles act as a drug delivery system, improving the therapeutic effect, prolonging the 


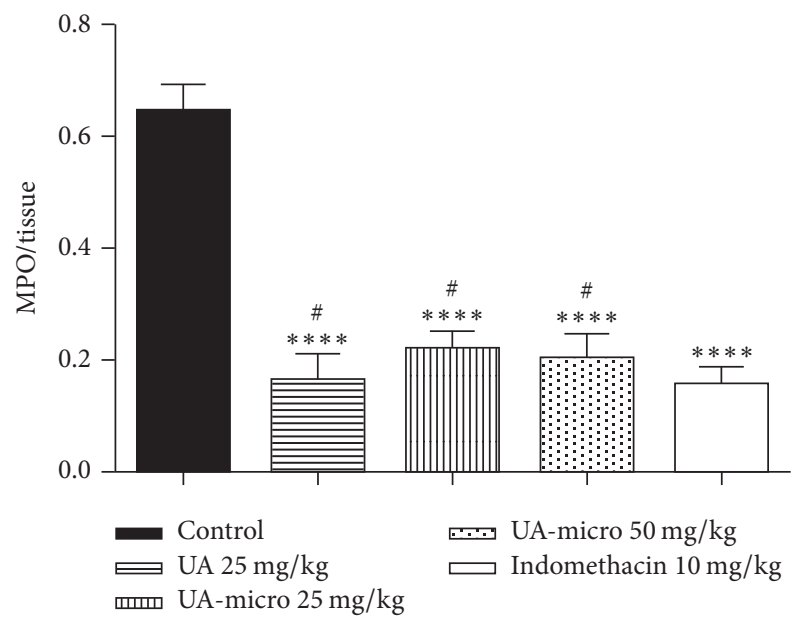

FIgURE 3: Effect of free usnic acid (UA), encapsulated usnic acid microspheres (UA-micro), or indomethacin on myeloperoxidase (MPO) levels in the subplantar tissue of rats paw. Values were expressed as mean $\pm \mathrm{SD} .{ }^{* * * *} p<0.0001$. ${ }^{\#}$ Nonsignificant versus indomethacin.

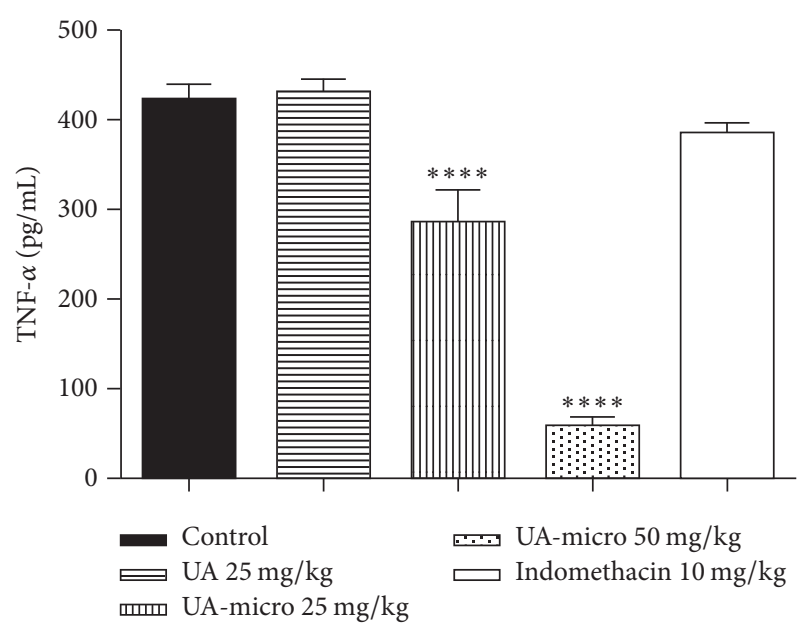

Figure 4: Effect of free usnic acid (UA), encapsulated usnic acid microspheres (UA-micro), or indomethacin regarding TNF$\alpha$ concentration in the inflammatory exudate from subcutaneous air pouch test. Values were expressed as mean $\pm S D$, and statistical significance between groups was determined using Analysis of Variance (ANOVA) followed by Tukey's test. ${ }^{* * *} p<0.0001$.

biological activity, controlling the drug release rate, decreasing the administration frequency, and so forth. These drug delivery systems protect certain labile active principles from degradation and/or inactivation by gastric juice, improve bioavailability by increasing the cellular penetration of substances, and provide release of the drug at the desired site of action, decreasing the toxic effects that normally accompany conventional therapy [28]. Regarding UA acute toxicity, our results corroborate with those found by Navarro et al. [29] which registered $100 \%$ death in mice treated with UA $(2000 \mathrm{mg} / \mathrm{kg}$; p.o.). Examination of liver and kidney tissue of animals treated with UA showed significant histopathological

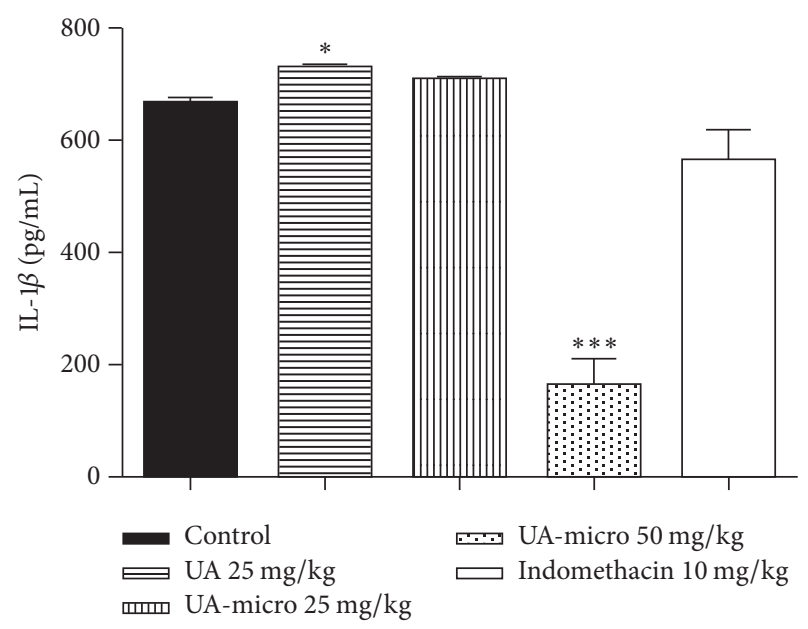

FIgURE 5: Effect of free usnic acid (UA), encapsulated usnic acid microspheres (UA-micro), or indomethacin on IL- $1 \beta$ concentration in the inflammatory exudate from subcutaneous air pouch test. Values were expressed as mean $\pm \mathrm{SD}$, and statistical significance between groups was determined using Analysis of Variance (ANOVA) followed by Tukey's test. ${ }^{*} p<0.01$; $^{* * *} p<0.001$.

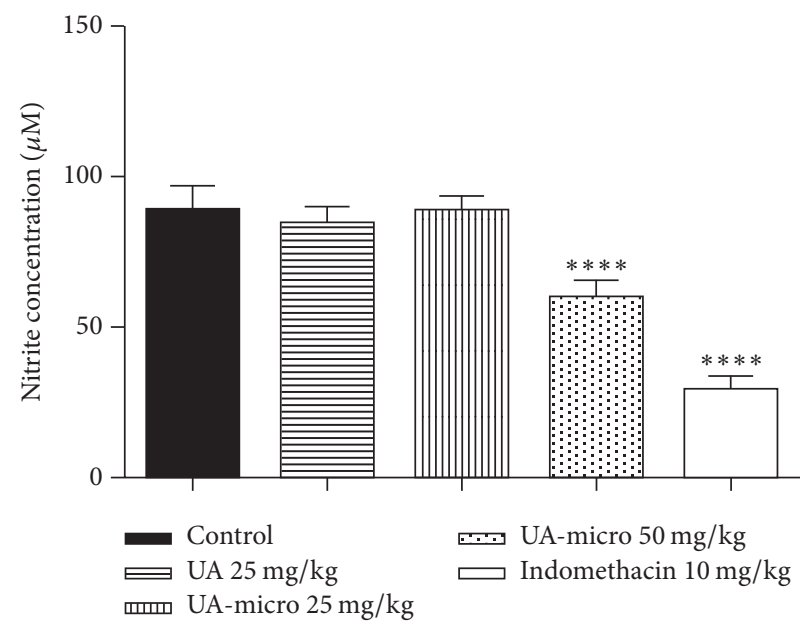

FIgURE 6: Effect of free usnic acid (UA), encapsulated usnic acid microspheres (UA-micro), or indomethacin regarding NO $(\mu \mathrm{M})$ concentration in the inflammatory exudate from subcutaneous air pouch test. Values were expressed as mean \pm SD, and statistical significance between groups was determined using Analysis of Variance (ANOVA), followed by Tukey's test. ${ }^{* * * *} p<0.0001$.

changes. Important liver architectural alterations (hepatic cell plates derangement, intense vacuolation, inflammatory influx, cytoplasmic acidophilia, and decharacterization of the nucleus of hepatocytes) were observed in mice treated with UA ( $2000 \mathrm{mg} / \mathrm{kg}$; p.o.), whereas at the same dose UA-microtreated animals showed plates of hepatic cells and sinusoids but preserved hepatocytes nuclei. Pramyothin et al. [30] found that UA acts altering cell membrane integrity, allowing for hepatic-specific enzymes release, mainly transaminases, 
causing mitochondrial function impairment, which culminates in cellular respiration control loss. In USA, hepatocellular damage was demonstrated when subjects ingested LipoKinetix ${ }^{\circledR}$, a dietary supplement that contains UA [31]. According to Han et al. [32], this kind of damage happens due to the increase in reactive oxygen species production through the electron transport chain, which leads to cellular death. da Silva Santos et al. [12] study liver alterations in mice treated with UA and also showed morphological changes (hepatic cell plates derangement and inflammatory infiltrate). In this study, UA encapsulation into PLGA (poly(lactic-co-glycolic acid)) nanocapsules decreased the hepatotoxicity in vivo. To the best of our knowledge, studies related to histopathological alterations in the renal morphology of animals treated with UA have not been established to date. Kidney tissue sections of UA animals showed prominent renal damage including intense nuclear acidophilia and cytoplasmic vacuolation, capsular space and convoluted tubules lumen size increase, fluid accumulation between the basal membrane and cuboidal epithelial cells of the convoluted tubes, and cytoplasmic material accumulation in the renal tubules and cell lysis. On the other hand, the UA-micro-treated group $(2000 \mathrm{mg} / \mathrm{kg}$; p.o.) showed slight derangement of the simple cuboidal epithelium of convoluted tubules and vacuolation presence, while renal corpuscles were kept preserved. The mechanisms that underlie kidney injury following UA treatment remain unclear. Further insight into these histological considerations needs further investigation.

The results in the present study indicated that free UA and UA-micro attenuated the carrageenan-induced rat paw edema and the levels of MPO (one inflammatory signal secreted after polymorphonuclear leukocytes are stimulated) into injured paw. Neutrophil granules myeloperoxidase (MPO) is involved in reactive oxygen production, free radicals, and membrane oxidation, and tissue MPO levels become higher during inflammatory conditions, which are commonly related with bacterial lysis and tissue oxidative injury [33]. Inflammatory cells, such as neutrophils and macrophages, play an important role in the inflammatory process through proinflammatory mediator secretion, including NO, TNF- $\alpha$, and IL- $1 \beta$ [34]. In addition, a decrease in the leukocytes migration and TNF- $\alpha$, IL- $1 \beta$, and NO levels in the inflammatory exudate from subcutaneous air pouch was also registered. TNF- $\alpha$ and IL- $1 \beta$ are related to increase of vascular permeability and migration of cells that produce chemokines [35]. The results of our study corroborate with those developed by Vijayakumar et al. [23], which showed anti-inflammatory activity of UA in carrageenan-induced rat paw edema, and Huang et al. [6], which demonstrated that the anti-inflammatory effect of UA is related to the negative regulation of iNOS, IL- $1 \beta$, and TNF- $\alpha$. Overall, the results of the current study indicate that equivalent or greater antiinflammatory activity was observed as UA was incorporated into poly- $\varepsilon$-caprolactone microsphere polymers (UA-micro).

\section{Conclusion}

UA is now shown to achieve equivalent or greater anti-inflammatory activity as it is incorporated into poly- $\varepsilon$-caprolactone microsphere polymers (UA-micro) compared to free UA, with greatly reduced acute toxicity.

\section{Conflicts of Interest}

The authors have no conflicts of interest to declare.

\section{Acknowledgments}

This paper is financially supported by O Conselho Nacional de Desenvolvimento Científico e Tecnológico (CNPq).

\section{References}

[1] K. J. Tracey, "The inflammatory reflex," Nature, vol. 420, no. 6917, pp. 853-859, 2002.

[2] B. Schlansky and J. H. Hwang, "Prevention of nonsteroidal antiinflammatory drug-induced gastropathy," Journal of Gastroenterology, vol. 44, no. 19, pp. 44-52, 2009.

[3] M. A. S. Coutinho, M. F. Muzitano, and S. S. Costa, "Flavonoides: Potenciais Agentes Terapêuticos para o Processo Inflamatório," Rev. Virtual Quim, vol. 3, pp. 241-256, 2009.

[4] K. Ingólfsdóttr, "Usnic acid," Phytochemistry, vol. 61, no. 7, pp. 729-736, 2002.

[5] Index Merck, An enciclopedia of Chemicals, Drugs and Biological, Rahway Merck \& Co., 11th edition, 1995.

[6] Z. Huang, G. Zheng, J. Tao, and J. Ruan, "Anti-inflammatory effects and mechanisms of usnic acid," Journal of Wuhan University of Technology-Mater. Sci. Ed., vol. 26, no. 5, pp. 955959, 2011

[7] S. Weckesser, K. Engel, B. Simon-Haarhaus, A. Wittmer, K. Pelz, and C. M. Schempp, "Screening of plant extracts for antimicrobial activity against bacteria and yeasts with dermatological relevance," Phytomedicine, vol. 14, no. 7-8, pp. 508-516, 2007.

[8] T. K. Rabelo, F. Zeidán-Chuliá, L. M. Vasques et al., "Redox characterization of usnic acid and its cytotoxic effect on human neuron-like cells (SH-SY5Y)," Toxicology in Vitro, vol. 26, no. 2, pp. 304-314, 2012.

[9] E. Einarsdóttir, J. Groeneweg, G. G. Björnsdóttir et al., "Cellular mechanisms of the anticancer effects of the lichen compound usnic acid," Planta Medica, vol. 76, no. 10, pp. 969-974, 2010.

[10] M. Bruno, B. Trucchi, B. Burlando et al., "(+)-Usnic acid enamines with remarkable cicatrizing properties," Bioorganic \& Medicinal Chemistry, vol. 21, no. 7, pp. 1834-1843, 2013.

[11] T. Kristmundsdóttir, E. Jónsdóttir, H. M. Ögmundsdóttir, and K. Ingólfsdóttir, "Solubilization of poorly soluble lichen metabolites for biological testing on cell lines," European Journal of Pharmaceutical Sciences, vol. 24, no. 5, pp. 539-543, 2005.

[12] N. P. S. da Silva Santos, S. C. Nascimento, M. S. O. Wanderley et al., "Nanoencapsulation of usnic acid: improvement on the antitumour activity and reduction of hepatotoxicity," European Journal of Pharmaceutics and Biopharmaceutics, vol. 64, no. 2, pp. 154-160, 2006.

[13] E. Garbayo, E. Ansorena, J. L. Lanciego, M. S. Aymerich, and M. J. Blanco-Prieto, "Sustained release of bioactive glycosylated glial cell-line derived neurotrophic factor from biodegradable polymeric microspheres," European Journal of Pharmaceutics and Biopharmaceutics, vol. 69, no. 3, pp. 844-851, 2008.

[14] C. Wischke and S. P. Schwendeman, "Principles of encapsulating hydrophobic drugs in PLA/PLGA microparticles," International Journal of Pharmaceutics, vol. 364, no. 2, pp. 298327, 2008. 
[15] R. M. Ribeiro-Costa, A. J. Alves, N. P. Santos et al., "In vitro and in vivo properties of usnic acid encapsulated into PLGAmicrospheres," Journal of Microencapsulation, vol. 21, no. 4, pp. 371-384, 2004.

[16] F. Ito, H. Fujimori, H. Honnami, H. Kawakami, K. Kanamura, and K. Makino, "Study of types and mixture ratio of organic solvent used to dissolve polymers for preparation of drugcontaining PLGA microspheres," European Polymer Journal, vol. 45 , no. 3 , pp. 658-667, 2009.

[17] OECD, 2001.Guideline for testing of chemicals 423: Acute oral toxicity. 14.

[18] C. A. Winter, E. A. Risley, and G. W. Nuss, "Carrageenininduced edema in hind paw of the rat as an assay for antiiflammatory drugs," Proceedings of the Society for Experimental Biology and Medicine, vol. 3, pp. 544-547, 1962.

[19] R. K. Mussi, E. A. Camargo, T. Ferreira et al., "Exercise training reduces pulmonary ischaemia-reperfusion-induced inflammatory responses," European Respiratory Society, vol. 31, no. 3, pp. 645-649, 2008.

[20] Y. M. Sin, A. D. Sedgwick, E. P. Chea, and D. A. Willoughby, "Mast cells in newly formed lining tissue during acute inflammation: A six day air pouch model in the mouse," Annals of the Rheumatic Diseases, vol. 45, no. 10, pp. 873-877, 1986.

[21] A. S. H. Da Silva Guerra, D. J. Do Nascimento Malta, L. P. Morais Laranjeira et al., "Anti-inflammatory and antinociceptive activities of indole-imidazolidine derivatives," International Immunopharmacology, vol. 11, no. 11, pp. 1816-1822, 2011.

[22] J. Xu, X. Xu, and W. Verstraete, "Adaptation of E. Coli cell method for micro-scale nitrate measurement with the Griess reaction in culture media," Journal of Microbiological Methods, vol. 41, no. 1, pp. 23-33, 2000.

[23] C. S. Vijayakumar, S. Viswanathan, M. Kannappa Reddy, S. Parvathavarthini, A. B. Kundu, and E. Sukumar, "Anti-inflammatory activity of (+)-usnic acid," Fitoterapia, vol. 71, no. 5, pp. 564-566, 2000.

[24] S. Parveen and S. K. Sahoo, "Long circulating chitosan/PEG blended PLGA nanoparticle for tumor drug delivery," European Journal of Pharmacology, vol. 670, no. 2-3, pp. 372-383, 2011.

[25] D. Klose, F. Siepmann, J. F. Willart, M. Descamps, and J. Siepmann, "Drug release from PLGA-based microparticles: Effects of the "microparticle:bulk fluid" ratio," International Journal of Pharmaceutics, vol. 383, no. 1-2, pp. 123-131, 2010.

[26] R. M. Ribeiro-Costa, M. R. D. Cunha, M. R. Gongora-Rubio, P. Michaluart-Júnior, and M. I. Ré, "Preparation of proteinloaded-PLGA microspheres by an emulsion/solvent evaporation process employing LTCC micromixers," Powder Technology, vol. 190, no. 1-2, pp. 107-111, 2009.

[27] D. R. Chen, J. Z. Bei, and S. G. Wang, "Polycaprolactone microparticles and their biodegradation," Polymer Degradation and Stability, vol. 67, no. 3, pp. 455-459, 2000.

[28] H. Fessi and F. Puisieux, Procédé de préparation dês sytemes colloidaux despersibles d'une substance sous forme de nanocapsules, European Patent, 1998.

[29] E. G. Navarro, J. A. Ávila, P. P. Mollinedo, J. L. C. Vila, and G. P. Ruiz, "Valoración de la toxicidad aguda in vivo del ácido úsnico," Revista Boliviana de Química, vol. 27, pp. 89-93, 2010.

[30] P. Pramyothin, W. Janthasoot, N. Pongnimitprasert, S. Phrukudom, and N. Ruangrungsi, "Hepatotoxic effect of (+) usnic acid from Usnea siamensis Wainio in rats, isolated rat hepatocytes and isolated rat liver mitochondria," Journal of Ethnopharmacology, vol. 90, no. 2-3, pp. 381-387, 2004.
[31] G. W. Neff, K. Rajender Reddy, F. A. Durazo, D. Meyer, R. Marrero, and N. Kaplowitz, "Severe hepatotoxicity associated with the use of weight loss diet supplements containing ma huang or usnic acid," Journal of Hepatology, vol. 41, no. 6, pp. 1062-1064, 2004.

[32] D. Han, K. Matsumaru, D. Rettori, and N. Kaplowitz, "Usnic acid-induced necrosis of cultured mouse hepatocytes: inhibition of mitochondrial function and oxidative stress," Biochemical Pharmacology, vol. 67, no. 3, pp. 439-451, 2004.

[33] J. Arnhold, "Free radicals-friends or foes: Properties, functions, and secretion of human myeloperoxidase," Biochemistry, vol. 69, pp. 8-15, 2004.

[34] J. P. Benincá, J. B. Dalmarco, M. G. Pizzolatti, and T. S. Fröde, "Analysis of the anti-inflammatory properties of Rosmarinus officinalis L. in mice," Food Chemistry, vol. 124, no. 2, pp. 468475, 2011.

[35] M. U. Martin and H. Wesche, "Summary and comparison of the signaling mechanisms of the Toll/interleukin-1 receptor family," Biochimica et Biophysica Acta (BBA)-Molecular Cell Research, vol. 1592, no. 3, pp. 265-280, 2002. 


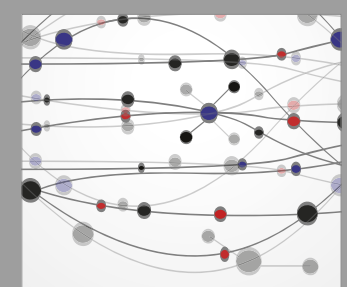

The Scientific World Journal
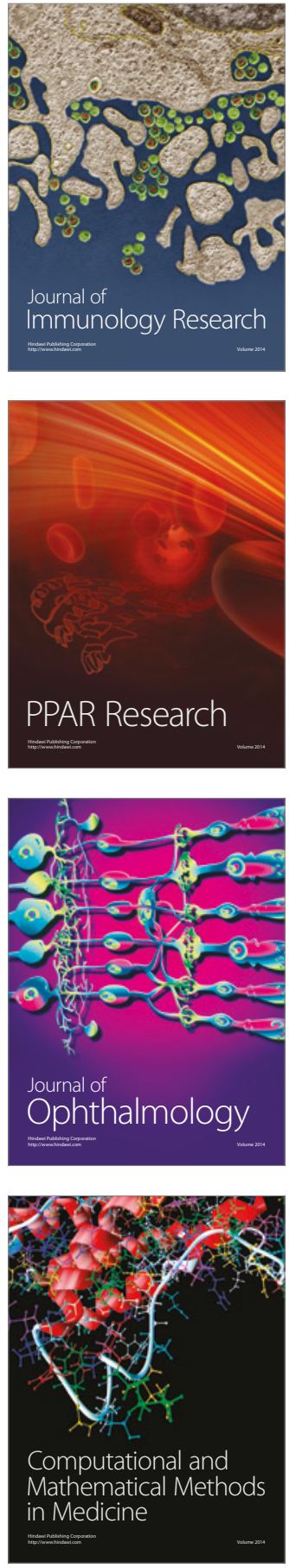

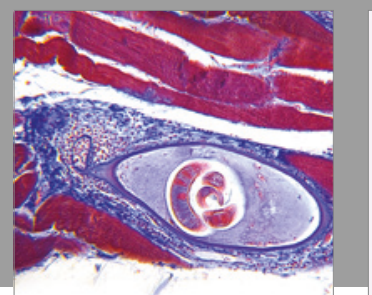

Gastroenterology Research and Practice
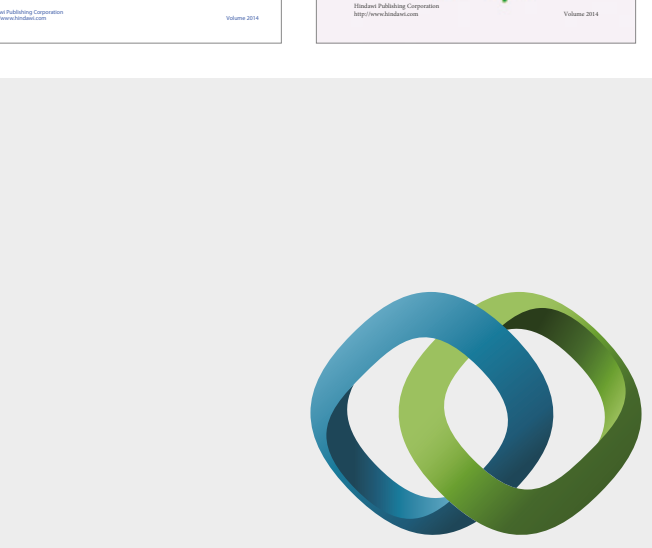

\section{Hindawi}

Submit your manuscripts at

https://www.hindawi.com
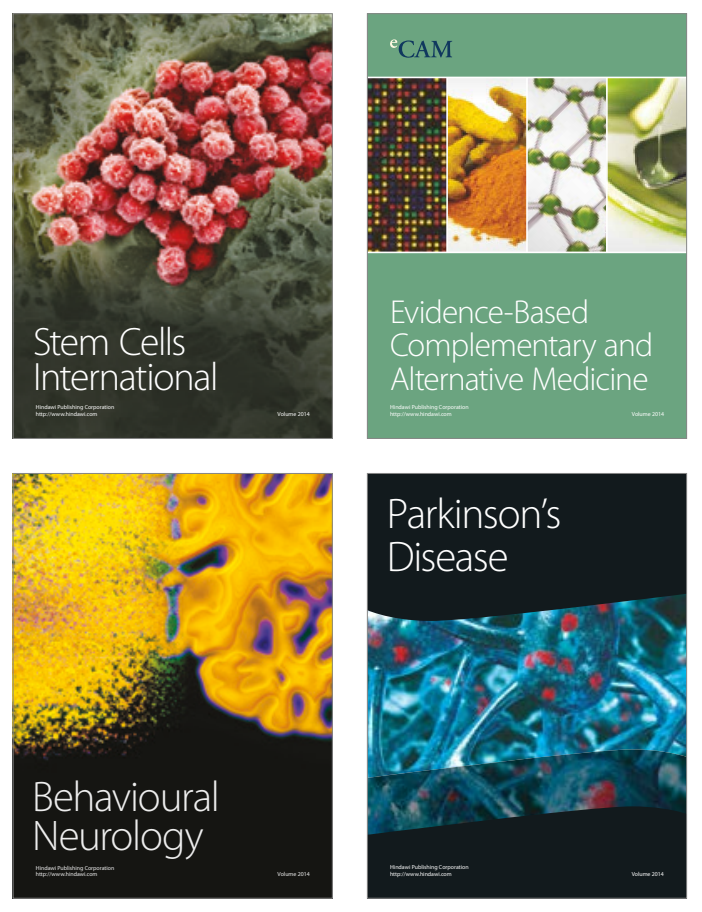
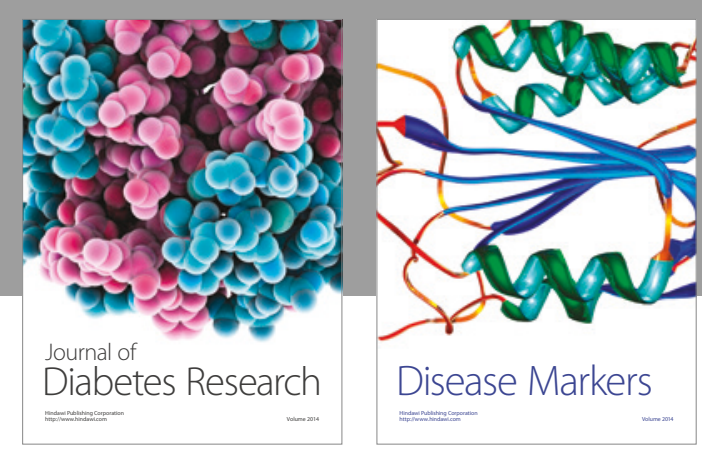

Disease Markers
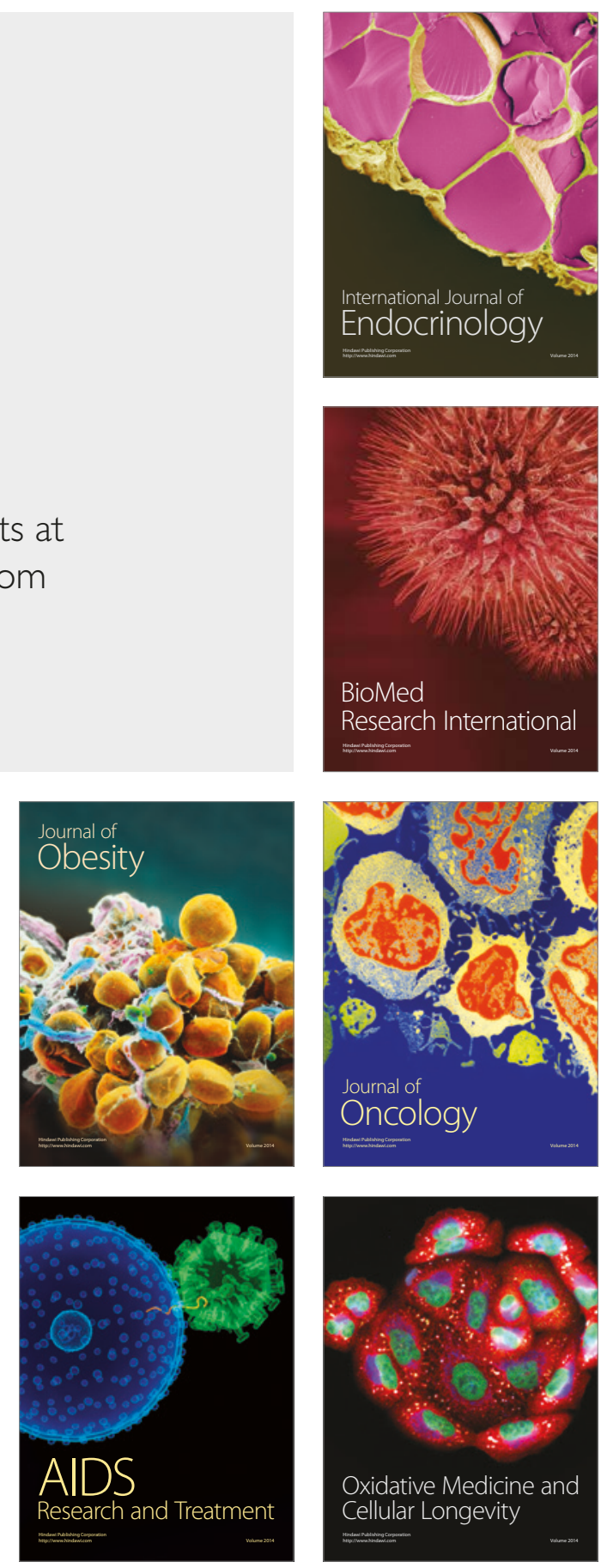